\title{
Recommended Handling Temperature
}

National Cancer Institute

\section{Source}

National Cancer Institute. Recommended Handling Temperature. NCI Thesaurus. Code C101683.

The recommended temperature of the environment when handling or operating a device. 